\title{
Implementasi Strategi Komunikasi Guru (SKG) dalam Pembelajaran untuk Meningkatkan Hasil Belajar Bahasa Inggris
}

\section{Ni Nengah Sumarni ${ }^{1 *}$}

${ }^{1}$ SMK Negeri 2 Negara, Jembrana, Indonesia

\section{A R T I C L E I N F O}

Article history:

Received 19 February 2021

Received in revised form 30 March 2021

Accepted 10 April 2021

Available online 11 May 2021

\section{Kata Kunci:}

Strategi Komunikasi Guru, Hasil Belajar.

Keywords:

Teacher Communication

Strategy, Learning

Outcomes.

\begin{abstract}
A B S T R A K
Rendahnya hasil belajar Bahasa Inggris siswa disebabkan penggunaan strategi pembelajaran yang kurang tepat, sehingga diperlukan strategi pembelajaran yang mampu memotivasi siswa untuk belajar dan mampu meningkatkan hasil belajar siswa. Penelitian ini bertujuan untuk menganalisis implementasi Strategi Komunikasi Guru (SKG) dalam pembelajaran untuk meningkatkan hasil belajar Bahasa Inggris. Penelitian ini merupakan penelitian tindakan kelas (PTK). Subjek penelitian ini adalah siswa Kelas $\mathrm{XI}$, dan objek penelitian ini adalah kemampuan belajar Bahasa Inggris siswa. Metode pengumpulan data yang digunakan adalah dengan metode pemberian tes. Teknik analisis data yang digunakan adalah teknik analisis data statistik kuantitatif. Hasil penelitian menunjukkan peningkatan hasil belajar siswa terlihat dari jumlah siswa yang tuntas belajar pada pra siklus sebesar $63,9 \%$, siklus I sebesar $88,9 \%$, dan siklus II sebesar 97,2\%. Simpulan penelitian ini adalah implementasi Strategi Komunikasi Guru (SKG) dalam
\end{abstract} pembelajaran terbukti dapat meningkatkan hasil belajar Bahasa Inggris siswa. Implikasi penelitian ini yaitu dengan pengimplementasian Strategi Komunikasi Guru (SKG) dalam pembelajaran dapat membangun suasana pembelajaran yang produktif, kreatif, dan inovatif.

\begin{abstract}
A B S T R A K
The low learning outcomes of students' English is due to the use of inappropriate learning strategies, so that learning strategies are needed that are able to motivate students to learn and be able to improve student learning outcomes. This study aims to analyze the implementation of the Teacher Communication Strategy (SKG) in learning to improve English learning outcomes. This research is a classroom action research (PTK). The subjects of this study were students of class XI, and the object of this research was the students' ability to learn English. The data collection method used is the method of giving tests. The data analysis technique used is quantitative statistical data analysis techniques. The results showed an increase in student learning outcomes seen in the number of students who completed learning in the pre-cycle was $63.9 \%$, the first cycle was $88.9 \%$, and the second cycle was $97.2 \%$. The conclusion of this research is that the implementation of the Teacher Communication Strategy (SKG) in learning has been proven to improve students' English learning outcomes. The implication of this research is that the implementation of the Teacher Communication Strategy (SKG) in learning can build a productive, creative, and innovative learning atmosphere.
\end{abstract}

\section{Pendahuluan}

Guru merupakan faktor dominan dalam proses pembelajaran sehingga sangat berpengaruh terhadap proses dan hasil belajar. Menurut (Dardiri et al., 2017; Karom et al., 2014; Umi et al., 2019) Guru merupakan jabatan atau profesi yang memerlukan suatu keahlian khusus, pekerjaannya tidak dapat dilakukan oleh sembarang orang tanpa memiliki keahlian sebagai guru. Guru merupakan seseorang yang mengabdikan diri dalam dunia pendidikan dan pembelajaran dengan berbagai syarat dan ketentuan yang 
sudah ditetapkan. Guru dapat dikatakan sebagai faktor penting dan strategis dalam proses pembelajaran untuk menghasilkan peserta didik yang berkualitas di samping faktor-faktor lainya. Karena, melalui guru proses transfer ilmu ke siswa didik dapat berjalan. Interaksi guru dan siswa yang berjalan dengan baik dapat menghasilkan perubahan perilaku dan pengetahuan pada peserta didik. Penting dan strategisnya peran guru khususnya terhadap masa depan anak didik, sehingga ekspektasi (pengharapan) masyarakat terhadap profesionalisme dan optimalisasi kinerjanya di sekolah kian besar. Sedikitnya ada tiga pilar utama yang menunjukkan bahwa guru telah bekerja secara optimal dan profesional dalam melaksanakan tugas-tugas kependidikannya, yakni: (a) menguasai materi pelajaran; (b) profesional untuk menyampaikan materi pembelajaran kepada siswa; dan (c). berkepribadian matang (Larasati \& Gafur, 2018; Sakti et al., 2019; Sutarno et al., 2011).

Berdasarkan hasil observasi di SMK Negeri 2 Negara, secara umum kemampuan guru khususnya yang berkenaan dengan strategi komunikasi-menunjukkan gejala yang kian memprihatinkan. Sebagian besar guru misalnya, faktanya masih menghadapi banyak kesulitan untuk mengorganisir dan mengkoordinasikan kemauan siswa dalam menyelesaikan tugas-tugasnya. Kecenderungan ini dikhawatirkan dapat berakibat negatif terhadap suasana pembelajaran di kelas, yang pada gilirannya dapat pula merusak motivasi dan prestasi belajar siswa. Pada dasarnya faktor penyebab seorang guru kesulitan di dalam merancang dan menerapkan strategi komunikasi yang efektif kepada siswa di kelas, di antaranya adalah minimnya pengalaman mengajar, rendahnya pengetahuan guru tentang teori dan praktek komunikasi yang efektif, serta rendahnya penguasaan guru terhadap penerapan strategi komunikasi secara tepat dan benar. Kondisi rendahnya penguasaan guru tentang strategi komunikasi ini, agaknya berdampak pada kesulitan dalam mengkondisikan suasana pembelajaran yang kondusif di kelas. Indikasinya, suasana kelas terlihat ribut atau gaduh, siswa tidak menunjukkan sikap serius dan disiplin selama proses pembelajaran berlangsung. Minat siswa terhadap materi pelajaran yang disampaikan oleh guru pun menjadi sangat menurun, bahkan tidak jarang ada siswa yang berani membolos karena menghindari pertemuan dengan guru dalam proses pembelajaran. Sehingga diperlukan strategi pembelajaran yang tepat salah satunya adalah Strategi Komunikasi Guru (SKG).

Strategi pada hakikatnya adalah perencanaan (planning) dan manajemen (management) untuk mencapai suatu tujuan (Khofiatun et al., 2016; Maiza \& Nurhafizah, 2019; Wardana, 2018). Tetapi untuk mencapai tujuan tersebut, strategi tidak berfungi sebagai peta jalan yang hanya menunjukkan arah saja, melainkan harus menunjukkan bagaimana taktik operasionalnya. Strategi dapat diartikan sebagai suatu proses penentuan rencana para pemimpin puncak yang berfokus pada tujuan jangka panjang organisasi, disertai penyusunan suatu cara atau upaya bagaimana tujuan tersebut dapat di capai (Ananda \& Fadhilaturrahmi, 2018; Fatimah, 2017; Sayekti \& Kinasih, 2018). Strategi komunikasi guru adalah pemahaman antara beberapa gabungan kata yaitu strategi, komunikasi, dan juga guru. Sedangkan strategi berarti segala cara dan daya untuk menghadapi sasaran tertentu dalam kondisi tertentu agar memperoleh hasil yang diharapkan secara maksimal. Demikian pula dengan strategi komunikasi guru yang merupakan paduan perencanaan komunikasi guru (communication planning) dan manajemen komunikasi guru (communication management) untuk mencapai tujuan yang telah diterapkan (Fitriyadi, 2013; Nuryani et al., 2016; Sudiran, 2015). Strategi komunikasi guru ini harus mampu menunjukkan bagaimana operasionalnya secara praktis dilakukan, dalam arti kata bahwa pendekatan (approach) bisa berbeda sewaktu waktu bergantung pada situasi dan kondisi, sungguh besar peran penting komunikasi dalam strategi pendidikan, karena itu komunikasi sangat baik untuk dipelajari dan dilakukan dalam ketercapaian tujuan pendidikan.

Komunikasi merupakan suatu hal yang sangat mendasar dalam kehidupan manusia, bahkan komunikasi telah menjadi suatu fenomena bagi terbentuknya suatu masyarakat atau komunitas yang terintegerasi oleh informasi, dimana masing masing individu dalam masyarakat itu sendiri saling berbagi informasi untuk mencapai tujuan bersama (Deswita \& Kusumah, 2018; Hartini et al., 2016; Purnama \& Aldila, 2016). Secara sederhana komunikasi dapat tercapai apabila ada kesamaan antara penyampai pesan dan orang yang menerima pesan. Dalam proses komunikasi ini biasanya berbentuk bahasa, gerakan gerakan yang memiliki makna khusus dan aba aba. Sedangkan komunikasi dalam proses sekunder berlangsung dengan bantuan mekanisme yang dapat melipat gandakan jumlah penerima pesan atau ditunjukan untuk mengatasi berbagai macam hambatan fisik/ kebendaan/jasadiah yang akan menghalangi komunikasi primer.

Tiga pilar tersebut dalam fungsinya saling berhubungan dan saling mendukung untuk meningkatkan kinerja pembelajaran. Kinerja pembelajaran menentukan tingkat keberhasilan dan kesesuaian hasil belajar siswa dengan tujuan yang telah ditentukan. Sedangkan tingkat keberhasilan dan kesesuaian hasil belajar siswa dengan tujuan sangat dipengaruhi oleh kinerja guru, yang salah satunya ditunjukkan oleh tingkat profesionalismenya dalam menyampaikan materi pembelajaran di kelas. Dalam hal ini, maka salah satu aspek yang perlu diperhatikan seorang guru adalah penguasaan terhadap strategi 
komunikasi. Penguasaan strategi komunikasi merupakan kemampuan dasar dan vital yang harus dimiliki seorang pendidik guna mendukung ketercapaian kompetensi/subkompetensi dalam pembelajaran (Nuryani et al., 2016; Rizta \& Antari, 2018; Sudiran, 2015).

Melalui penerapan strategi komunikasi yang efektif diharapkan seorang guru mampu mengorganisasi dan mengkoordinasi kemauan siswa untuk menyelesaikan tujuan pendidikannya, sehingga siswa dapat belajar dalam suasana yang menyenangkan (enjoyfull learning), dan beraktifitas tinggi baik secara mental, fisik, sosial, maupun emosinya (Rizta \& Antari, 2018; Togatorop, 2017; Wahyuni et al., 2016). Hal tersebut baru bisa dicapai jika didukung oleh kepribadian guru yang matang dan kesadaran untuk mengelola proses pembelajaran dengan menaati dan menetapkan azas-azas didaktik dalam setiap momentum yang tepat khususnya di ruang kelas. Melalui penerapan strategi komunikasi yang efektif ini seorang guru diharapkan dapat membangun suasana pembelajaran yang produktif, kreatif, dan inovatif, yaitu suatu pembelajaran yang mampu meningkatkan mutu lulusan, dengan demikian, kemampuan metodik-didaktis menjadi titik sentral pembelajaran dan perlu terus dikembangkan secara professional (Ardina \& Sa'dijah, 2016; Siregar, 2019; Yerizon et al., 2020).

Penelitian ini didukung beberapa penelitian-penelitian sebelumnya yang relevan dengan penelitian ini seperti: (1) penlitian yang dilaksanakan oleh (Hapsari et al., 2019), yang mendapatkan hasil bahwa strategi guru menggunakan pendekatan saintifik dapat meningkatkan hasil belajar; (2) penlitian yang dilaksanakan oleh (Widodo, 2014), yang mendapatkan hasil bahwa strategi pembelajaran terbukti dapat meningkatkan aktivitas jasmani siswa sekolah dasar di luar pembelajaran PJOK; (3) penlitian yang dilaksanakan oleh (Rizal \& Munip, 2017), yang mendapatkan hasil bahwa Strategi Guru Kelas dalam pembelajaran dapat menumbuhkan nilai-nilai karakter didalam diri siswa.

Tujuan penelitian tindakan kelas (PTK) ini adalah untuk menganalisis implementasi Strategi Komunikasi Guru (SKG) dalam pembelajaran untuk meningkatkan hasil belajar Bahasa Inggris siswa Kelas XI T0.1 SMK Negeri 2 Negara Semester 1 Tahun Pelajaran 2018/2019.

\section{Metode}

Penelitian ini merupakan penelitian tindakan kelas (PTK), yang dilaksanakan di SMK Negeri 2 Negara dimana sekolah ini lingkungannya cukup baik dalam mendukung lancarnya pelaksanaan proses belajar mengajar karena aman, nyaman, rindang, tidak bising serta masyarakat sekitar mendukung keberadaan sekolah dengan baik. Dipilihnya Kelas XI TO.1 Semester 1 Tahun Pelajaran 2018/2019 sebagai subjek penelitian karena penulis adalah guru yang sedang mengajar di kelas tersebut. Subjek penelitian ini adalah siswa Kelas XI T0.1 SMK Negeri 2 Negara sebanyak 36 orang yang terdiri dari 36 orang siswa laki-laki. Dipilihnya siswa. Yang dijadikan objek penelitian ini adalah kemampuan belajar Bahasa Inggris siswa Kelas XI TO.1 SMK Negeri 2 Negara yang masih rendah. Kemampuan belajar Bahasa Inggris dipilih sebagai objek penelitian yang akan diperbaiki mengingat kemampuan dalam pembelajaran Bahasa Inggris sangat penting dikuasai oleh siswa dalam menguasai kemampuan mata pelajaran lainnya.

Metode pengumpulan data pada penelitian ini adalah dengan metode pemberian tes. Penelitian dilaksanakan pada semester 1 Tahun Pelajaran 2018/2019 selama 3 bulan yakni bulan Juli s.d. September 2018. Data tentang setiap aktivitas belajar siswa dilihat dengan menggunakan format observasi aktivitas siswa, kemudian ditabulasikan, apakah aktifitasnya meningkat atau tidak. Hasil data ini dapat dinyatakan dengan baik atau kurang baik. Teknik analisis data yang digunakan pada penelitian ini adalah teknik analisis data statistik kuantitatif. Adapun Indikator keberhasilan penelitian tindakan ini adalah bila terjadi peningkatan aktifitas belajar dan hasil belajar siswa yang dihitung berdasarkan prosentase pada setiap siklusnya. Kriteria hasil belajar siswa menggunakan rata-rata tes ulangan harian. Sekurang-kurangnya siswa lulus secara klasikal sebanyak 70\%. Siswa lulus secara individual jika nilai yang diperoleh minimal 70 (sesuai kriteria ketuntasan minimal mata pelajaran Bahasa Inggris SMK Negri 2 Negara). Untuk keaktifan siswa dikatakan berhasil bila mencapai prosentase baik yaitu antara $61-80 \%$ dan sangat baik jika melebihi $80 \%$ siswa yang aktif. Dengan arti kata penelitian akan berhasil dan sangat baik jika ada peningkatan aktivitas belajar siswa mencapai $>80 \%$ setelah proses pembelajaran menggunakan strategi Komunikasi Guru (SKG).

\section{Hasil dan Pembahasan}

Kegiatan pembelajaran dilakukan 2 siklus. Siklus I dilakukan selama dua kali pertemuan (empat jam pelajaran), pertemuan ke-1 dilakukan kegiatan pembelajaran dengan mengamati aktivitas siswa dan guru dalam pembelajaran menggunakan strategi komunikasi guru, sedangkan kegiatan tes hasil belajar dilakukan pada pertemuan ke-2 sekaligus melaksanakan pembahasan serta perencanaan kegiatan pada siklus II. Hasil tindakan pada tiap siklus ditampilkan pada Tabel 1. 
Tabel 1. Rekapitulasi Aktivitas Belajar Siswa Selama Proses Pembelajaran

\begin{tabular}{|c|c|c|c|c|c|c|}
\hline \multirow{3}{*}{ Aspek Aktivitas Belajar Siswa } & \multicolumn{6}{|c|}{ Jumlah Siswa } \\
\hline & \multicolumn{2}{|c|}{ Pra Siklus } & \multicolumn{2}{|c|}{ Siklus I } & \multicolumn{2}{|c|}{ Siklus II } \\
\hline & Jumlah & $\%$ & Jumlah & $\%$ & Jumlah & $\%$ \\
\hline Siswa Giat Menerima Materi & 14 & 38.9 & 25 & 69.4 & 36 & 100.00 \\
\hline $\begin{array}{l}\text { Siswa Menemukan Hal-Hal Penting dan } \\
\text { Materi }\end{array}$ & 20 & 55.6 & 26 & 72.2 & 30 & 83.33 \\
\hline $\begin{array}{l}\text { Siswa Menunjukkan Kemampuan } \\
\text { Analisis }\end{array}$ & 19 & 52.8 & 25 & 69.4 & 29 & 80.56 \\
\hline Siswa Kritis dalam Berpikir & 20 & 55.6 & 24 & 66.7 & 30 & 83.33 \\
\hline $\begin{array}{l}\text { Kemampuan Memecahkan Masalah } \\
\text { Lewat Masalah }\end{array}$ & 19 & 52.8 & 26 & 72.2 & 29 & 80.56 \\
\hline $\begin{array}{l}\text { Siswa Cepat Menanggapi Tuntutan } \\
\text { Siswa Menunjukkan Kemampuan Lebih }\end{array}$ & 17 & 47.2 & 23 & 63.9 & 30 & 83.33 \\
\hline Memproses Sesuatu yang Bermakna & 16 & 44.4 & 22 & 61.1 & 29 & 80.56 \\
\hline Pembelajaran Berpusat pada Diri Siswa & 15 & 41.7 & 23 & 63.9 & 36 & 100.00 \\
\hline $\begin{array}{l}\text { Siswa Mampu Menelorkan Kesimpulan- } \\
\text { Kesimpulan }\end{array}$ & 17 & 47.2 & 25 & 69.4 & 36 & 100.00 \\
\hline Jumlah & & 436.1 & & 608.3 & & 791.67 \\
\hline Rata-Rata & & 48.46 & & 67.59 & & 87.96 \\
\hline Kategori & & C & & B & & $\mathbf{A B}$ \\
\hline
\end{tabular}

Dari data pada Tabel 1, diperoleh dari pelaksanaan observasi oleh pengamat terhadap aktivitas belajar siswa dengan mempergunakan strategi komunikasi guru dapat diketahui apakah aktivitas siswa rendah, cukup, tinggi atau tinggi sehingga dapat diketahui peningkatan aktivitas yang diharapkan. Aktivitas siswa pada tabel dapat diukur secara kualitatif dan kuantitatif.

Berdasarkan pedoman konversi aktivitas belajar siswa seperti pada 3.4 (Bab III), maka dapat ditarik suatu kesimpulan bahwa siswa telah menampakkan peningkatan aktivitas belajar dari rerata pada pra siklus 48,46 (Cukup) ke siklus I rerata 67,59 (Baik) maupun ke siklus II rerata 87,96 (Amat Baik). Selain aktivitas secara Individu. Dalam pelaksanaaan pembelajaran juga diamati aktivitas siswa secara kelompok, Adapun hasil pengamatan aktivitas siswa secara kelompok digambarkan seperti Tabel 2.

Tabel 2. Prosentase Kenaikan Kinerja pada Tiap Kelompok

\begin{tabular}{cccccc}
\hline Nama Kelompok & Pra Siklus & Siklus I & Siklus Ii & $\begin{array}{c}\text { \% Pra Skls Ke } \\
\text { Skls I }\end{array}$ & $\begin{array}{c}\text { \% Sikls I Ke } \\
\text { Skls Ii }\end{array}$ \\
\hline A & 63.00 & 75.00 & 92.00 & $18.68 \%$ & $22.90 \%$ \\
B & 60.00 & 74.00 & 88.00 & $21.79 \%$ & $18.86 \%$ \\
C & 70.00 & 78.00 & 90.00 & $12.45 \%$ & $16.16 \%$ \\
D & 64.00 & 70.00 & 87.00 & $9.34 \%$ & $22.90 \%$ \\
\hline Rata-Rata & $\mathbf{6 4 . 2 5}$ & $\mathbf{7 4 . 2 5}$ & $\mathbf{8 9 . 2 5}$ & $\mathbf{1 5 . 5 6 \%}$ & $\mathbf{2 0 . 2 0 \%}$ \\
\hline
\end{tabular}

Dari Tabel 2. diatas, diperoleh bahwa rata-rata prosentase kinerja kelompok terdapat kenaikan. Ini berarti bahwa implementasi strategi komunikasi guru (SKG) mampu memberikan kontribusi kepada siswa dalam proses pembelajaran secara signifikan. Di samping itu, kenaikan antar siklusnya juga mengalami peningkatan yaitu dari pra Siklus ke Siklus I naik 18,68\% menjadi 22,90\% dari Siklus I ke Siklus II. Dimana tingkat kehadiran siswa selama proses pembelajaran adalah $100 \%$.

Kegiatan untuk memperoleh data tentang hasil belajar siswa dilakukan tes. Tes hasil belajar dilakukan pada pertemuan ke-2 sekaligus melaksanakan pembahasan serta perencanaan kegiatan pada siklus II. Hasil belajar dari tindakan pada tiap siklus ditampilkan pada Tabel 3.

Tabel 3. Rekapitulasi Hasil Belajar Siswa pada Pra Siklus, Siklus I, dan Siklus II.

\begin{tabular}{cccccc}
\hline \multirow{2}{*}{ NIS } & \multirow{2}{*}{ Nama Siswa } & \multirow{2}{*}{ L/P } & \multicolumn{3}{c}{ Hasil Belajar } \\
\cline { 4 - 6 } & & & Pra Siklus & Siklus I & Siklus II \\
\hline 5347 & Alfian Kartika Cahyo Widodo & L & 70 & 80 & 90
\end{tabular}




\begin{tabular}{|c|c|c|c|c|c|}
\hline \multirow{2}{*}{ NIS } & \multirow{2}{*}{ Nama Siswa } & \multirow{2}{*}{$\mathbf{L} / \mathbf{P}$} & \multicolumn{3}{|c|}{ Hasil Belajar } \\
\hline & & & Pra Siklus & Siklus I & Siklus II \\
\hline 5348 & Dodik Eko Setiawan & $\mathrm{L}$ & 70 & 80 & 85 \\
\hline 5349 & Hendra Setiawan & $\mathrm{L}$ & 80 & 85 & 95 \\
\hline 5350 & I Gede Adi Wilasa & $\mathrm{L}$ & 65 & 78 & 80 \\
\hline 5351 & I Gede Ana Wibawa & $\mathrm{L}$ & 75 & 85 & 85 \\
\hline 5352 & I Gede Juni Arta & $\mathrm{L}$ & 70 & 80 & 82 \\
\hline 5353 & I Gede Mahendra Gupta & $\mathrm{L}$ & 76 & 80 & 81 \\
\hline 5354 & I Gusti Ngurah Kade Agus Pujana & $\mathrm{L}$ & 70 & 76 & 85 \\
\hline 5355 & I Kade Dwi Guna Darma Adnyana & $\mathrm{L}$ & 70 & 80 & 80 \\
\hline 5356 & I Kadekduwi Murtamayasa & $\mathrm{L}$ & 65 & 70 & 76 \\
\hline 5357 & I Kadek Dwi Mahendra & $\mathrm{L}$ & 70 & 76 & 90 \\
\hline 5358 & I Kadek Eka Sudarsa & $\mathrm{L}$ & 70 & 75 & 78 \\
\hline 5359 & I Kadek Swastika & $\mathrm{L}$ & 65 & 70 & 90 \\
\hline 5360 & I Ketut Andriana Putra & $\mathrm{L}$ & 70 & 72 & 76 \\
\hline 5361 & I Ketut Ardana & $\mathrm{L}$ & 60 & 74 & 80 \\
\hline 5362 & I Ketut Candra Adi Saputra Yasa & $\mathrm{L}$ & 75 & 75 & 85 \\
\hline 5363 & I Ketut Yudi Saputra & $\mathrm{L}$ & 75 & 78 & 78 \\
\hline 5364 & I Komang Agus Ariantika & $\mathrm{L}$ & 70 & 77 & 85 \\
\hline 5365 & I Komang Muliawan & $\mathrm{L}$ & 74 & 76 & 80 \\
\hline 5366 & I Made Dwi Aditya Prayoga & $\mathrm{L}$ & 85 & 85 & 85 \\
\hline 5367 & I Made Johny Gita Maulana & $\mathrm{L}$ & 75 & 75 & 75 \\
\hline 5368 & I Nengah Septa Aditya & $\mathrm{L}$ & 65 & 70 & 75 \\
\hline 5369 & I Putu Budiantara & $\mathrm{L}$ & 66 & 76 & 76 \\
\hline 5370 & I Putu Krisna Adi Pratama & $\mathrm{L}$ & 60 & 70 & 78 \\
\hline 5371 & I Putu Rudiawan & $\mathrm{L}$ & 70 & 77 & 80 \\
\hline 5372 & I Putu Sinar Arta & $\mathrm{L}$ & 75 & 80 & 80 \\
\hline 5373 & I Putu Tirta Semadi & $\mathrm{L}$ & 60 & 65 & 78 \\
\hline 5374 & I Wayan Suartika & $\mathrm{L}$ & 70 & 75 & 80 \\
\hline 5375 & Jhnny Walker Sukertia & $\mathrm{L}$ & 65 & 76 & 88 \\
\hline 5376 & Ketut Adhy Ardika & $\mathrm{L}$ & 75 & 75 & 87 \\
\hline 5377 & Komang Dedi Ardiyasa & $\mathrm{L}$ & 72 & 76 & 85 \\
\hline 5378 & Made Ardi Krisnanda & $\mathrm{L}$ & 70 & 70 & 78 \\
\hline 5379 & Muhammad Budi Permana & $\mathrm{L}$ & 60 & 65 & 70 \\
\hline 5380 & Riki Aoriyansah & $\mathrm{L}$ & 65 & 70 & 78 \\
\hline 5381 & Rizky Farhan Dharma Prasetya & $\mathrm{L}$ & 55 & 65 & 70 \\
\hline 5382 & Tri Wahyudi & $\mathrm{L}$ & 50 & 60 & 65 \\
\hline \multicolumn{3}{|c|}{ Jumlah } & 2478 & 2697 & 2909 \\
\hline \multicolumn{3}{|c|}{ Rata-Rata } & 68.83 & 74.92 & 80.81 \\
\hline \multicolumn{3}{|c|}{ Prosentase Ketuntasan } & 63.9 & 88.9 & 97.2 \\
\hline
\end{tabular}

Dari Tabel 3, terlihat adanya peningkatan rerata hasil belajar siswa pada mata pelajaran Bahasa inggris, pada pra siklus 68,83 naik menjadi 74,92 pada siklus I, dan menjadi 80,81 pada siklus II. Dimana tingkat kehadiran siswa saat diadakan tes adalah $100 \%$.

Jika ditinjau dari jumlah siswa yang tuntas adalah pada setiap siklusnya yaitu pada pra siklus 23 orang, dan 13 orang lainnya dinyatakan belum tuntas karena belum mencapai nilai 70 (sesuai dengan KKM). Sedangkan pada siklus I terdapat 32 siswa yang tuntas belajar dan 4 siswa yang belum tuntas. Pada siklus II jumlah siswa yang tuntas naik mencapai 35 orang dan 1 lainnya belum tuntas. Untuk lebih jelasnya perhatikan Tabel 4.

Tabel 4. Rekapitulasi Jumlah Siswa Tuntas dan Prosentasennya pada Setiap Siklus

\begin{tabular}{lcccc}
\hline \multirow{2}{*}{ Tes Tiap Siklus } & \multicolumn{2}{c}{ Tuntas } & \multicolumn{2}{c}{ Belum Tuntas } \\
\cline { 2 - 5 } & Jumlah & \% & Jumlah & \% \\
\hline Pra Siklus & 23 & 63.9 & 13 & 36.1 \\
Siklus I & 32 & 88.9 & 4 & 11.1 \\
Siklus II & 35 & 97.2 & 1 & 2.8 \\
\hline
\end{tabular}


Dari Tabel 4, jika ditinjau dari jumlah skor, rerata dan prosentase kenaikan ketuntasan pada setiap siklus dengan diterapkan strategi komunikasi guru (SKG) dalam pembelajaran Bahasa Inggris di kelas XI T0.1 Semester 1 SMK Negeri 2 Negara ternyata terdapat kenaikan aktivitas belajar siswa secara signifikan, pada tiap indikator aktivitas yang diamati. Untuk lebih jelasnya seperti tampak pada Tabel 5.

Tabel 5. Rekapitulasi Aktivitas Belajar Siswa Ditinjau dari Jumlah, Rerata, dan Presentase Peningkatan pada Setiap Siklus

\begin{tabular}{lccccc}
\hline \multirow{2}{*}{ Indikator } & \multicolumn{3}{c}{ Kegiatan } & \multicolumn{2}{c}{ Peningkatan Ketuntasan } \\
\cline { 2 - 6 } & \multirow{2}{*}{ Pra Siklus } & \multirow{2}{*}{ Siklus I } & \multirow{2}{*}{ Siklus II } & \multirow{2}{*}{ \%Pra Siklus ke Siklus I } & \%Siklus I ke Siklus \\
\hline Jumlah & 2478 & 2697 & 2909 & 219 & 212 \\
Rerata & 68.83 & 74.92 & 80.81 & 25.0 & 8.3 \\
\hline
\end{tabular}

Dari Tabel 5, terlihat adanya peningkatan hasil belajar Bahasa Inggirs, siswa kelas XI T0.1 Semester 1 SMK Negeri 2 Negara. Dengan jumlah 36 orang siswa yaitu sebagai berikut: pada pra siklus jumlah siswa yang tuntas adalah 23 orang, dan 13 orang lainnya dinyatakan belum tuntas karena belum mencapai nilai 70 (sesuai dengan KKM). Sedangkan pada siklus I terdapat 32 siswa yang tuntas belajar dan 4 siswa yang belum tuntas. Pada siklus II jumlah siswa yang tuntas naik mencapai 35 orang dan 1 lainnya belum tuntas. Dimana tingkat kehadiran siswa saat dilaksanakan tes adalah $100 \%$.

Karena jumlah siswa yang tuntas melebihi 75 \%, maka penelitian tindakan kelas yang dilakukan guru sudah berhasil. Artinya Implementasi Strategi Komunikasi guru (SKG) dalam melaksanakan pembelajaran mata pelajaran Bahasa Inggris terbukti dapat meningkatkan hasil belajar siswa. Adapun gambar grafik kenaikan jumlah siswa yang tuntas belajar untuk tiap siklus dapat dilihat pada Gambar 1 .

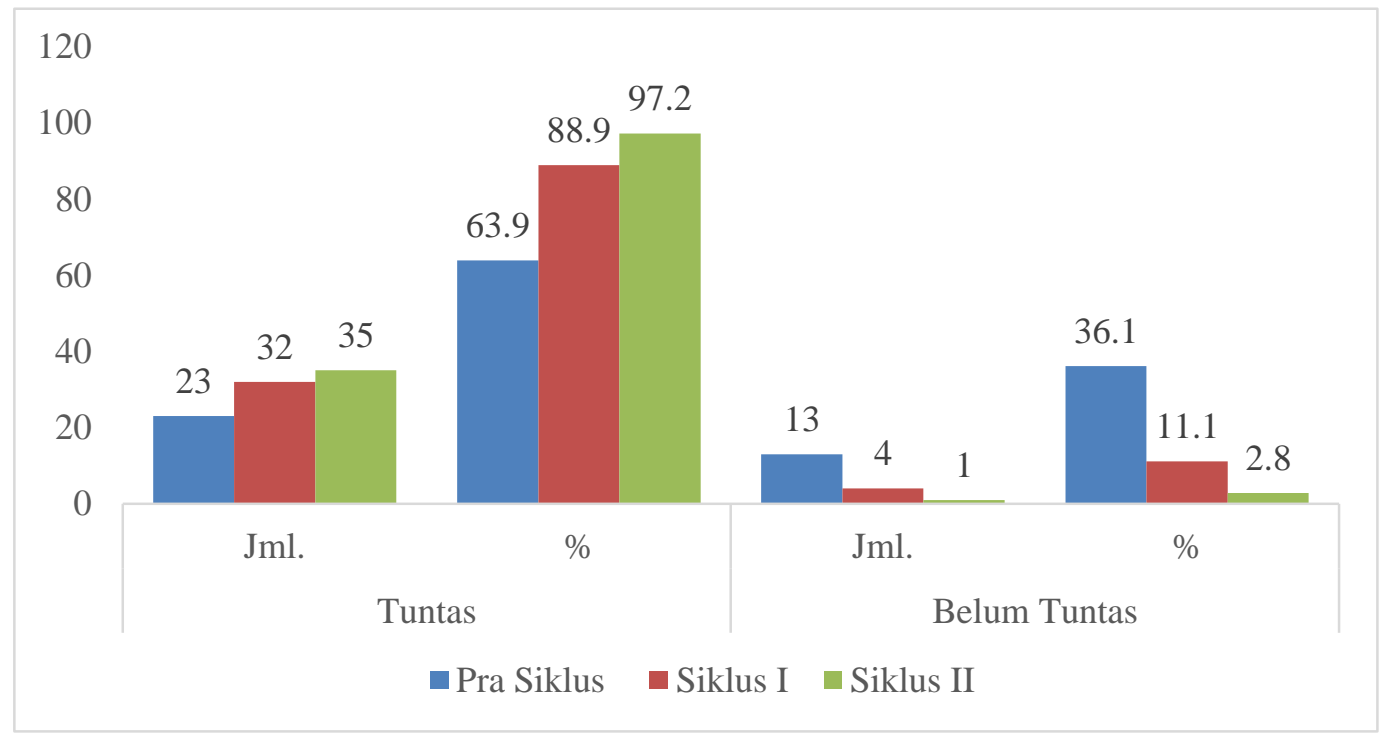

Gambar 1. Grafik Histogram Jumlah Tuntas, Belum Tuntas, dan Prosentase Ketuntasan pada Setiap Siklus

Berdasarkan Gambar 1, dapat disimpulkan bahwa implementasi Strategi Komunikasi Guru (SKG) dalam pembelajaran terbukti dapat meningkatkan hasil belajar Bahasa Inggris siswa siswa Kelas XI T0.1 SMK Negeri 2 Negara Semester 1 Tahun Pelajaran 2018/2019.

Strategi komunikasi guru adalah pemahaman antara beberapa gabungan kata yaitu strategi, komunikasi, dan juga guru. Sedangkan strategi berarti segala cara dan daya untuk menghadapi sasaran tertentu dalam kondisi tertentu agar memperoleh hasil yang diharapkan secara maksimal. Demikian pula dengan strategi komunikasi guru yang merupakan paduan perencanaan komunikasi guru (communication planning) dan manajemen komunikasi guru (communication management) untuk mencapai tujuan yang telah diterapkan (Fitriyadi, 2013; Nuryani et al., 2016; Sudiran, 2015). Strategi komunikasi guru ini harus mampu menunjukkan bagaimana operasionalnya secara praktis dilakukan, dalam arti kata bahwa pendekatan (approach) bisa berbeda sewaktu waktu bergantung pada situasi dan kondisi, sungguh besar peran penting komunikasi dalam strategi pendidikan, karena itu komunikasi sangat baik untuk dipelajari dan dilakukan dalam ketercapaian tujuan pendidikan. 
Komunikasi merupakan suatu hal yang sangat mendasar dalam kehidupan manusia, bahkan komunikasi telah menjadi suatu fenomena bagi terbentuknya suatu masyarakat atau komunitas yang terintegerasi oleh informasi, dimana masing masing individu dalam masyarakat itu sendiri saling berbagi informasi untuk mencapai tujuan bersama (Deswita \& Kusumah, 2018; Hartini et al., 2016; Purnama \& Aldila, 2016). Secara sederhana komunikasi dapat tercapai apabila ada kesamaan antara penyampai pesan dan orang yang menerima pesan. Dalam proses komunikasi ini biasanya berbentuk bahasa, gerakan gerakan yang memiliki makna khusus dan aba aba. Sedangkan komunikasi dalam proses sekunder berlangsung dengan bantuan mekanisme yang dapat melipat gandakan jumlah penerima pesan atau ditunjukan untuk mengatasi berbagai macam hambatan fisik/ kebendaan/jasadiah yang akan menghalangi komunikasi primer.

Melalui penerapan strategi komunikasi yang efektif diharapkan seorang guru mampu mengorganisasi dan mengkoordinasi kemauan siswa untuk menyelesaikan tujuan pendidikannya, sehingga siswa dapat belajar dalam suasana yang menyenangkan (enjoyfull learning), dan beraktifitas tinggi baik secara mental, fisik, sosial, maupun emosinya (Rizta \& Antari, 2018; Togatorop, 2017; Wahyuni et al., 2016). Hal tersebut baru bisa dicapai jika didukung oleh kepribadian guru yang matang dan kesadaran untuk mengelola proses pembelajaran dengan menaati dan menetapkan azas-azas didaktik dalam setiap momentum yang tepat khususnya di ruang kelas. Melalui penerapan strategi komunikasi yang efektif ini seorang guru diharapkan dapat membangun suasana pembelajaran yang produktif, kreatif, dan inovatif, yaitu suatu pembelajaran yang mampu meningkatkan mutu lulusan, dengan demikian, kemampuan metodik-didaktis menjadi titik sentral pembelajaran dan perlu terus dikembangkan secara professional (Ardina \& Sa'dijah, 2016; Siregar, 2019; Yerizon et al., 2020).

Penelitian ini didukung beberapa penelitian-penelitian sebelumnya yang relevan dengan penelitian ini seperti: (1) penlitian yang dilaksanakan oleh (Hapsari et al., 2019), yang mendapatkan hasil bahwa strategi guru menggunakan pendekatan saintifik dapat meningkatkan hasil belajar; (2) penlitian yang dilaksanakan oleh (Widodo, 2014), yang mendapatkan hasil bahwa strategi pembelajaran terbukti dapat meningkatkan aktivitas jasmani siswa sekolah dasar di luar pembelajaran PJOK; (3) penlitian yang dilaksanakan oleh (Rizal \& Munip, 2017), yang mendapatkan hasil bahwa Strategi Guru Kelas dalam pembelajaran dapat menumbuhkan nilai-nilai karakter didalam diri siswa.

Implikasi penelitian tindakan kelas ini adalah dengan pengimplementasian Strategi Komunikasi Guru (SKG) dalam pembelajaran Bahasa Inggris, maka dapat membangun suasana pembelajaran yang produktif, kreatif, dan inovatif.

\section{Simpulan}

Berdasarkan hasil penelitian dan pembahasan maka dapat disimpulkan bahwa implementasi Strategi Komunikasi Guru (SKG) dalam pembelajaran terbukti dapat meningkatkan hasil belajar Bahasa Inggris siswa siswa Kelas XI TO.1 SMK Negeri 2 Negara Semester 1 Tahun Pelajaran 2018/2019. Implikasi penelitian ini yaitu dengan pengimplementasian Strategi Komunikasi Guru (SKG) dalam pembelajaran dapat membangun suasana pembelajaran yang produktif, kreatif, dan inovatif.

\section{Daftar Rujukan}

Ananda, R., \& Fadhilaturrahmi, F. (2018). Analisis Kemampuan Guru Sekolah Dasar Dalam Implementasi Pembelajaran Tematik Di SD. Jurnal Basicedu, 2(2), 11-21. https://doi.org/10.31004/basicedu.v2i2.42

Ardina, F. R., \& Sa'dijah, C. (2016). Analisis Lembar Kerja Siswa Dalam Meningkatkan Komunikasi Matematis Tulis Siswa. Jurnal Pendidikan: Teori, Penelitian, Dan Pengembangan, 1(2), 171-180. https://doi.org/10.17977/jp.v1i2.6119

Dardiri, A., Mujiyono, M., \& Ichwanto, M. A. (2017). Analisis Hasil Uji Kompetensi Guru Sekolah Menengah Kejuran Bidang Keahlian Teknik Bangunan. Teknologi Dan Kejuruan: Jurnal Teknologi, Kejuruan, Dan Pengajarannya, 40(2), 193-203. https: //doi.org/10.17977/um031v40i22017p193

Deswita, R., \& Kusumah, Y. S. (2018). Peningkatan Kemampuan Komunikasi Matematis Siswa Melalui Model Pembelajaran CORE dengan Pendekatan Scientific. Edumatika: Jurnal Riset Pendidikan Matematika, 1(1), 35-43. https://doi.org/https://doi.org/10.32939/ejrpm.v1i1.220

Fatimah, S. (2017). Analisis Pemahaman Konsep IPA Berdasarkan Motivasi Belajar, Keterampilan Proses Sains, Kemampuan Multirepresentasi, Jenis Kelamin, Dan Latar Belakang Sekolah Mahasiswa Calon Guru SD. Jurnal Inovasi Pendidikan Dan Pembelajaran Sekolah Dasar, 1(1), 57-70. 
https://doi.org/10.24036/jippsd.v1i1.7934

Fitriyadi, H. (2013). Keterampilan TIK Guru Produktif SMK di Kabupaten Hulu Sungai Utara dan Implementasinya dalam Pembelajaran. Jurnal Pendidikan Vokasi, 2(2), 213-233. https://doi.org/10.21831/jpv.v2i2.1033

Hapsari, E. E., Sumantri, M. S., \& Astra, I. M. (2019). Strategi Guru Meningkatkan Hasil Belajar Menggunakan Pendekatan Saintifik Di Sekolah Dasar. Jurnal Basicedu, 3(2), 850-860. https://doi.org/10.31004/basicedu.v4i4.445

Hartini, H., Maharani, Z. Z., \& Rahman, B. (2016). Penerapan Model Pembelajaran Think-Pair-Share untuk Meningkatkan Kemampuan Komunikasi Matematis Siswa SMP. Kreano, Jurnal Matematika KreatifInovatif, 7(2), 131-135. https://doi.org/10.15294/kreano.v7i2.5009

Karom, D., Ruhimat, T., \& Darmawan, D. (2014). Pengaruh Kompetensi Pedagogik Guru Dalam Menerapkan Pembelajaran Kooperatif Berbantuan Media Presentasi Terhadap Hasil Belajar Peserta Didik Pada Mata Pelajaran Matematika. Edutech, 13(2), 274-308. https://doi.org/10.17509/edutech.v13i2.3113

Khofiatun, Akbar, S., \& Ramli, M. (2016). Peran Kompetensi Pedagogik Guru Dalam Pembelajaran Tematik Di Sekolah Dasar. Jurnal Pendidikan, 1(5), 984-988. https://doi.org/10.17977/jp.v1i5.6336

Larasati, V., \& Gafur, A. (2018). Hubungan kompetensi pedagogis dan kompetensi profesional guru PPKn dengan prestasi belajar siswa sekolah menengah. Jurnal Civics: Media Kajian Kewarganegaraan, 15(1), 45-51. https://doi.org/10.21831/jc.v15i1.17282

Maiza, Z., \& Nurhafizah, N. (2019). Pengembangan Keprofesian Berkelanjutan dalam Meningkatkan Profesionalisme Guru Pendidikan Anak Usia Dini. Jurnal Obsesi : Jurnal Pendidikan Anak Usia Dini, 3(2), 356-365. https://doi.org/10.31004/obsesi.v3i2.196

Nuryani, S., Hadisiwi, P., \& Karimah, K. El. (2016). Pola Komunikasi Guru Pada Siswa Anak Berkebutuhan Khusus Di Sekolah Menengah Kejuruan Inklusi. Jurnal Kajian Komunikasi, 4(2), 154-171. https://doi.org/https://doi.org/10.24198/jkk.v4i2.6134

Purnama, I. L., \& Aldila, E. (2016). Kemampuan Komunikasi Matematis Siswa Ditinjau Melalui Model Pembelajaran Kooperatif Tipe Complete Sentence Dan Team Quiz. Jurnal Pendidikan Matematika, 10(1). https://doi.org/10.1.3267.26-41

Rizal, S., \& Munip, A. (2017). Strategi Guru Kelas dalam Menumbuhkan Nilai-Nilai Karakter Pada Siswa SD/MI. Al Ibtida: Jurnal Pendidikan Guru MI, 4(1), 45. https://doi.org/10.24235/al.ibtida.snj.v4i1.1462

Rizta, A., \& Antari, L. (2018). Pengembangan Tes Kemampuan Komunikasi Matematis Pada Materi Sistem Persamaan Linear Untuk Mahasiswa Calon Guru Matematika. Aksioma: Jurnal Program Studi Pendidikan Matematika, 7(2), 291-299. https://doi.org/10.24127/ajpm.v7i2.1525

Sakti, T. K., Hairunisya, N., \& Sujai, I. S. (2019). Pengaruh Kompetensi Pedagogik Guru dan Gaya Belajar Siswa Terhadap Prestasi Belajar Siswa Pada Mata Pelajaran IPS. Jurnal Pendidikan Ilmu Sosial, 28(1), 53-60. https://doi.org/10.17509/jpis.v28i1.12818

Sayekti, I. C., \& Kinasih, A. M. (2018). Kemampuan Guru Menerapkan Keterampilan Proses Sains Dalam Pembelajaran IPA Pada Siswa Kelas Iv B Sdm 14 Surakarta. Profesi Pendidikan Dasar, 1(1), 93. https://doi.org/10.23917/ppd.v1i1.4464

Siregar, R. M. R. (2019). Pengaruh Model Pembelajaran Kooperatif Tipe Time Token Terhadap Kemampuan Komunikasi Matematika Siswa. MathEducation Nusantara, 2(1), 35-38. https://doi.org/10.32696/jmn.v2i1.58

Sudiran. (2015). Sikap Guru dan Tingkat Penggunaan Teknologi Informasi dan Komunikasi di Kelas Sebagai Media Pembelajaran Bahasa Inggris di SMA 3 dan SMK 1 Muhammadiyah Kota Batu. JINoP (Jurnal Inovasi Pembelajaran), 1(1), 98-112. https://doi.org/10.22219/jinop.v1i1.2452

Sutarno, H., Rohendi, D., \& Putri, G. G. (2011). Pengaruh Kompetensi Guru. Jurnal Pengajaran MIPA, 53(16), 134-14. https://doi.org/10.1017/CB09781107415324.004

Togatorop, M. (2017). Pengembangan Model Pembelajaran Co-Op Co-Op Berbantu Teknologi Inforamsi Dan Komunikasi (Tik) Pada Mata Pelajaran Ekonomi. Satya Widya, 33(2), 128-145. https://doi.org/10.24246/j.sw.2017.v33.i2.p128-145 
Umi, R., Nopriansyah, U., \& Purnama, S. (2019). Korelasi Kepemimpinan Kepala Taman Kanak-Kanak Terhadap Kinerja Kompetensi Pedagogik dan Kompetensi Profesional Guru. Al-Athfaal: Jurnal Ilmiah Pendidikan Anak Usia Dini, 2(1). https://doi.org/10.24042/ajipaud.v2i1.4552

Wahyuni, R., Utami, C., \& Husna, N. (2016). Pengaruh Model Role Playing Terhadap Kemampuan Komunikasi Matematis Siswa Pada Materi Fungsi Komposisi Kelas XI Sma Negeri 6 Singkawang. JPMI (Jurnal Pendidikan Matematika Indonesia), 1(2), 81. https://doi.org/10.26737/jpmi.v1i2.87

Wardana. (2018). Peningkatkan Kompetensi Guru Sekolah Dasar Dalam Mengimplementasikan Standar Proses Pembelajaran Melalui Supervisi Kolegial Teknik Kunjungan Antar Kelas. Jurnal Tarbawi, 15(1), 93-112. https://doi.org/10.34001/tarbawi.v15i1.721

Widodo. (2014). Strategi Peningkatan Aktivitas Jasmani Siswa Sekolah Dasar di Luar Pembelajaran Pendidikan Jasmani, Olahraga, dan Kesehatan di Indonesia. Jurnal Pendidikan Dan Kebudayaan, 20(2), 281-294. https://doi.org/10.24832/jpnk.v20i2.144

Yerizon, Y., Putri, Y. U., Musdi, E., \& Permana, D. (2020). Efektivitas Perangkat Pembelajaran Matematika Berbasis Pendekatan Contextual Teaching and Learning Terhadap Kemampuan Komunikasi Matematis. AKSIOMA: Jurnal Program Studi Pendidikan Matematika, 9(1), 205-212. https://doi.org/10.24127/ajpm.v9i1.2305 